\title{
Development of Ni-based multilayers for future focusing soft gamma ray telescopes
}

Girou, David A.; Massahi, Sonny; Sleire, Erlend K.; Jakobsen, Anders C.; Christensen, Finn E.

\section{Published in:}

Proceedings of SPIE

Link to article, DOI:

$10.1117 / 12.2186814$

Publication date:

2015

Document Version

Publisher's PDF, also known as Version of record

Link back to DTU Orbit

Citation (APA):

Girou, D. A., Massahi, S., Sleire, E. K., Jakobsen, A. C., \& Christensen, F. E. (2015). Development of Ni-based multilayers for future focusing soft gamma ray telescopes. In Proceedings of SPIE (Vol. 9603, pp. 11). SPIE International Society for Optical Engineering. Proceedings of SPIE - The International Society for Optical Engineering https://doi.org/10.1117/12.2186814

\section{General rights}

Copyright and moral rights for the publications made accessible in the public portal are retained by the authors and/or other copyright owners and it is a condition of accessing publications that users recognise and abide by the legal requirements associated with these rights.

- Users may download and print one copy of any publication from the public portal for the purpose of private study or research.

- You may not further distribute the material or use it for any profit-making activity or commercial gain

- You may freely distribute the URL identifying the publication in the public portal 


\title{
Development of Ni-based multilayers for future focusing soft gamma ray telescopes
}

\author{
David A. Girou, Sonny Massahi, Erlend K. Sleire, Anders C. Jakobsen and Finn E. \\ Christensen \\ DTU Space, National Space Institute, Elektrovej, 2800 Kgs. Lyngby, Denmark
}

\begin{abstract}
Ni-based multilayers are a possible solution to extend the upper energy range of hard X-ray focusing telescopes currently limited at $\approx 79.4 \mathrm{keV}$ by the Pt-K absorption edge. In this study 10 bilayers multilayers with a constant bilayer thickness were coated with the DC magnetron sputtering facility at DTU Space, characterized at $8 \mathrm{keV}$ using X-ray reflectometry and fitted using the IMD software. Ni/C multilayers were found to have a mean interface roughness $\approx 1.5$ times lower than $\mathrm{Ni} / \mathrm{B}_{4} \mathrm{C}$ multilayers. Reactive sputtering with $\approx 76 \%$ of $\mathrm{Ar}$ and $\approx 24 \%$ of $\mathrm{N}_{2}$ reduced the mean interface roughness by a factor of $\approx 1.7$. It also increased the coating rate of $\mathrm{C}$ by a factor of $\approx 3.1$ and lead to a coating process going $\approx 1.6$ times faster. Honeycomb collimation proved to limit the increase in mean interface roughness when the bilayer thickness increases at the price of a coating process going $\approx 1.9$ times longer than with separator plates. Finally a Ni/C 150 bilayers depth-graded mutilayer was coated with reactive sputtering and honeycomb collimation and then characterized from $10 \mathrm{keV}$ to $150 \mathrm{keV}$. It showed $10 \%$ reflectance up to $85 \mathrm{keV}$.
\end{abstract}

Keywords: nickel, multilayer, X-ray, gamma-ray, telescope, depth-graded, reactive sputtering, collimation, coating, magnetron sputtering

\section{INTRODUCTION}

The hard X-ray focusing telescopes on the NuSTAR mission ${ }^{1}$ and to be flown on the ASTRO-H mission ${ }^{2}$ use depth-graded multilayer coatings to extend the energy bandwidth to the hard X-ray range. For both missions the upper energy range is limited to $\approx 79.4 \mathrm{keV}$ by the platinum $\mathrm{K}$ absorption edge of the constituent heavy material. One possible solution for extending the energy bandwidth into the soft gamma ray range of several hundred $\mathrm{keV}$ is to use nickel $(\mathrm{Ni})$ as the heavy element in the multilayer as this material does not have absorption edges in hard X-ray/soft gamma ray range (Ni K absortion edge is at $\approx 8.3 \mathrm{keV}$ ). The challenge is to deposit smooth enough layers to get closer to theoretical reflectances. This paper reports on our current status of developing these coatings in the direct current (DC) magnetron sputtering facility at DTU Space including the combined methods of collimation and reactive sputtering using molecular nitrogen $\left(\mathrm{N}_{2}\right)$.

This study was carried out first by investigating individually three main multilayer coating parameters which are the material combination, the gas composition and the collimation method. For each investigation of a parameter a multilayer coating was deposited on a silicon $(\mathrm{Si})$ substrate in the DC magnetron sputtering facility at DTU Space. Then $8.047 \mathrm{keV}$ X-ray reflectometry (XRR) was performed, also at DTU Space. Finally the IMD software package ${ }^{3}$ was used to characterize the layers deposited (thicknesses and roughnesses).

Subsequently a depth-graded multilayer coating was deposited using selected values for the parameters investigated in the first part of the study. This depth-graded multilayer coating was then characterized in the laboratory-based hard X-ray reflectometer at the Reflective X-ray Optics LLC (RXO) ${ }^{4}$ in New York City.

Further author information:

Send correspondence to

D.A.G.: e-mail: girou@space.dtu.dk

F.E.C.: e-mail: finn@space.dtu.dk, telephone: +45 35325734

Optics for EUV, X-Ray, and Gamma-Ray Astronomy VII, edited by Stephen L. O'Dell, Giovanni Pareschi, Proc. of SPIE Vol. 9603, 96031D - () 2015 SPIE · CCC code: 0277-786X/15/\$18 · doi: 10.1117/12.2186814 


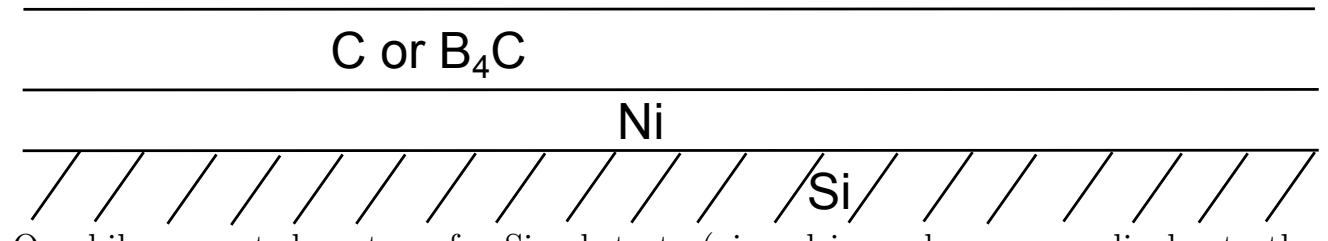

Figure 1: One bilayer coated on top of a Si substrate (viewed in a plane perpendicular to the surface of the substrate)

\section{INVESTIGATION OF COATING METHODS}

The multilayer coatings investigated in this section consist of 10 bilayers with a light material, carbon (C) or boron carbide $\left(\mathrm{B}_{4} \mathrm{C}\right)$, on top of a heavy material, Ni. The substrate used is a piece of Si of thickness $\approx 0.8 \mathrm{~mm}$ with a surface roughness of $\approx 2.5 \AA$. The surface coated is a rectangle of $1 \times 7 \mathrm{~cm}^{2}$. Figure 1 shows one bilayer coated on top of a Si substrate. In this section the thickness of each bilayer (also called d-spacing) is the same for the 10 bilayers in one coating and is called multilayer period. Moreover the gamma value $\Gamma$ is defined here and for this entire paper as the ratio of the thickness of the heavy material layer, $z_{N i}$, and the bilayer thickness, $d$, such as

$$
\Gamma=\frac{z_{N i}}{d} \approx 0.4
$$

The DC magnetron sputtering facility at DTU Space is a high vacuum chamber $\left(<10^{-6}\right.$ Torr $)$ in which an inert gas, argon (Ar), is used during the coating process. Moreover a reactive gas such as $\mathrm{N}_{2}$ can be added. The sputtering process is then called reactive sputtering. The composition of the gas filling the chamber impacts the coating process in ways investigated hereafter. The pressure of the gas (coating pressure) during the coatings presented through out this paper is $\approx 2.9$ mTorr. It was found that a coating pressure $<2.3 \mathrm{mTorr}$ is likely to lead to power dropouts during the coating. A power dropout is an interval of time during which the plasma is not sustained and therefore during which no material is deposited. This can lead to large errors in bilayer thicknesses and $\Gamma$ values.

The coating process is also impacted by the path traveled by the atoms of the sputtered material from the target (made of the desired material) to the Si substrate. ${ }^{5}$ Collimation techniques are ways to select desired paths. In one configuration two separator plates are placed parallel to each other at a distance of 100 mm, perpendicularly to the coated surface (one about $50 \mathrm{~mm}$ above the substrate and one about $50 \mathrm{~mm}$ below it). In a second configuration a honeycomb grid is placed parallel to the substrate at a distance of about $4 \mathrm{~cm}$ from the target on one side and about $8 \mathrm{~cm}$ from the substrate on the other side. Figure 2a is a picture of a Si substrate fixed on a mounting plate and two separator plates separated from each other by 100 mm. Figure $2 \mathrm{~b}$ is a picture of a honeycomb grid placed in front of a Ni target. Note that only one of these collimations is used at once. The influence of these collimation techniques are studied hereafter as well.

To study the impact of a parameter, for each multilayer coating carried out XRR was performed. The X-ray machine at DTU Space consists, among other components, of a copper rotating anode and the energy extracted with a monochromator corresponds to the K-alpha emission line of copper (8.047 keV). Then two main parameters were derived from an IMD fit. One, directly retrieved, is the mean roughness which corresponds to the mean value of all the interface roughnesses (for ten $\mathrm{Ni} / \mathrm{C}$ or $\mathrm{Ni} / \mathrm{B}_{4} \mathrm{C}$ bilayers these corresponds to nine interfaces with a layer of $\mathrm{C}$ or $\mathrm{B}_{4} \mathrm{C}$ on top of layer of $\mathrm{Ni}$, ten interfaces with a layer of $\mathrm{Ni}$ on top of a layer of $\mathrm{C}$ or $\mathrm{B}_{4} \mathrm{C}$ and one top interface with vacuum on top of $\mathrm{C}$ ) except for the interface with Ni on top of the Si surface of the substrate which was set to $2.5 \AA$ as specified by the manufacturer. The other, derived from the fitted bilayer period, is the coating rate or the thickness of material deposited per unit of time. This coating rate is different for each material. The mean roughness matters when a high number of bilayers are deposited (more than 100) since the roughness accumulates and leads to poor reflectances. The coating rate is important for high number of bilayers coatings due to time consumption (up to 12 hours for NuSTAR coatings ${ }^{6}$ ). Note that for each figure and each table the number of data sets is stated, this is the number of Si substrates coated, measured 


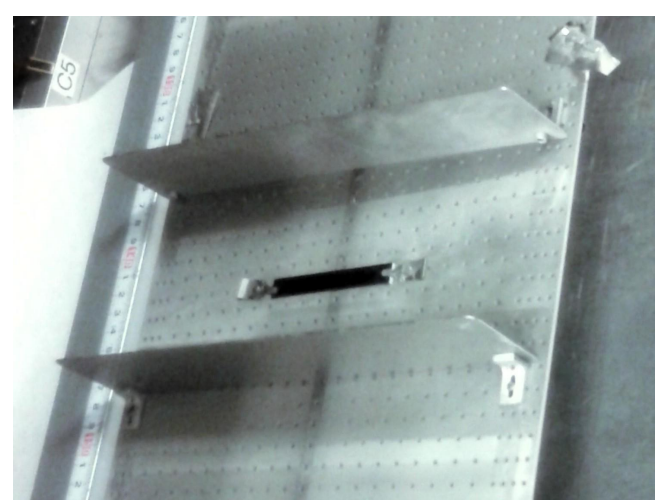

(a) Separator plates and Si substrate

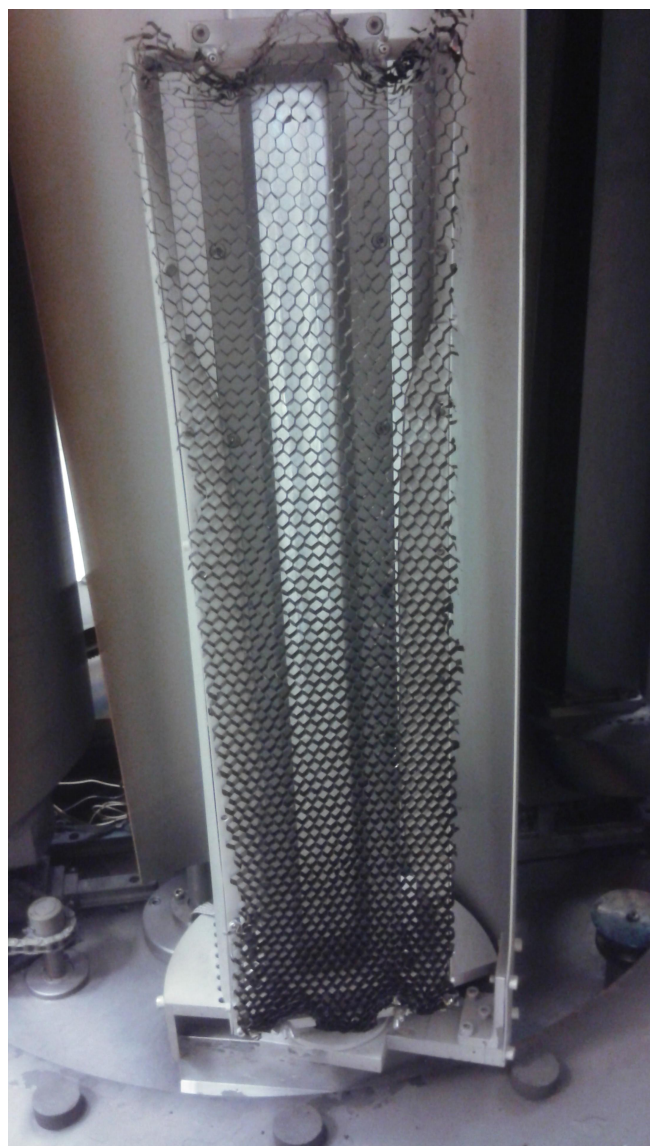

(b) Honeycomb in front of Ni target

Figure 2: Different collimations

with XRR and fitted with IMD per point or value. When two or more values are used for one data point, the error bars correspond to the standard deviation while when only one value is used the error bars correspond to an estimation of the goodness of a manual fit.

\subsection{Material combination}

The heavy material used in the multilayer coatings investigated here is Ni. Two light materials, $\mathrm{C}$ and $\mathrm{B}_{4} \mathrm{C}$ were used as well. This leads to the two material combinations referred to as $\mathrm{Ni} / \mathrm{C}$ and $\mathrm{Ni} / \mathrm{B}_{4} \mathrm{C}$.

Figure 3 is a plot of the fitted mean roughness as a function of fitted bilayer period for each material combination. These coatings were performed with a coating pressure of $\approx 2.90$ mTorr with about $76 \%$ of Ar and $\approx 24 \%$ of $\mathrm{N}_{2}$, with separator plates and the fitted $\Gamma$ value is $\approx 0.43$. At both low bilayer periods $(\approx 25 \AA)$ and relatively high bilayer periods $(\approx 60 \AA)$ the fitted mean roughness is $\approx 1.47$ times lower with $\mathrm{Ni} / \mathrm{C}$. Note as well that the mean roughness increase with the increase of bilayer period.

Table 1 displays the fitted mean roughness for two bilayer periods $(\approx 25 \AA$ and $\approx 60 \AA)$ as well as the coating rates of the light and heavy materials for each material combination. The coating parameters are the same as the one from Figure 3. The coating rates of $\mathrm{C}$ and $\mathrm{B}_{4} \mathrm{C}$ do not significantly differ. 


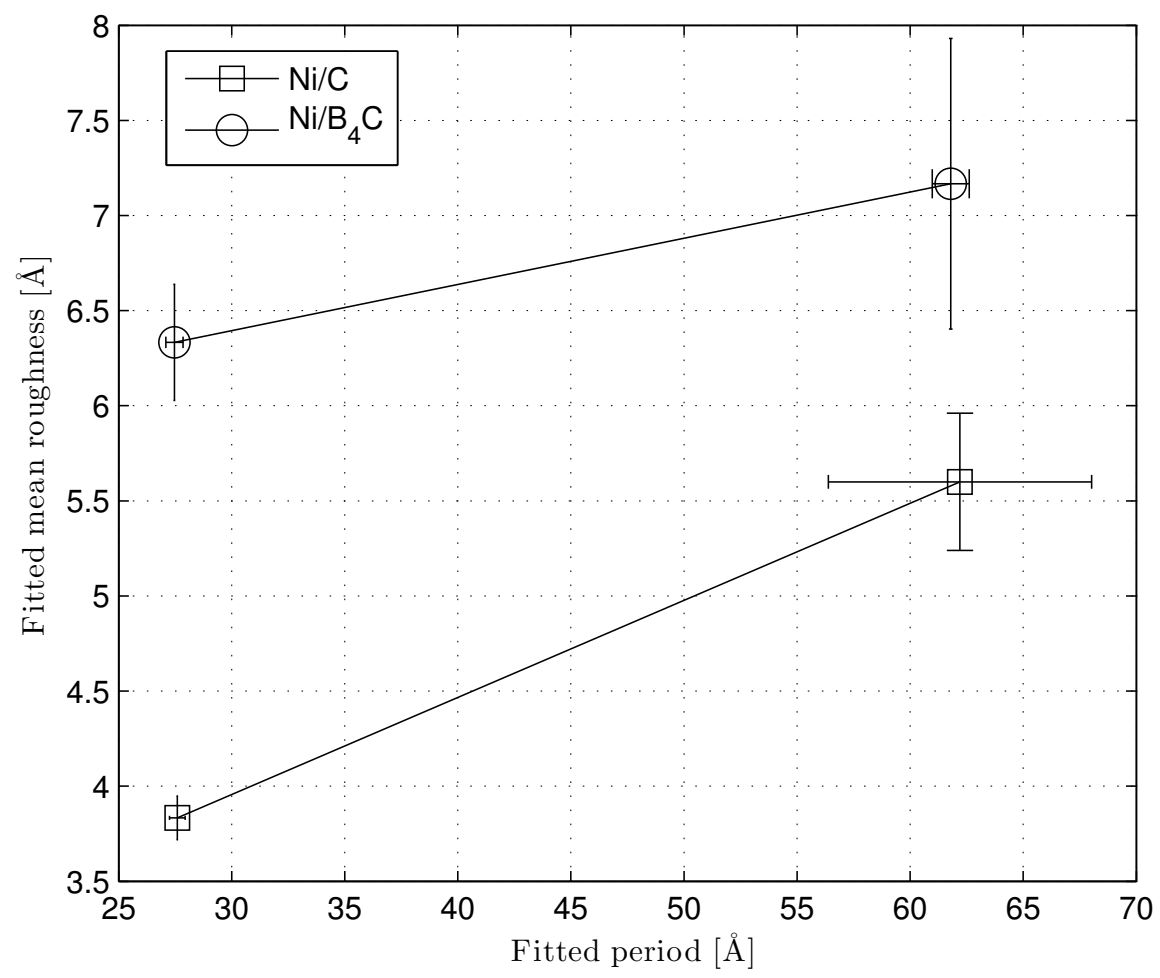

Figure 3: Impact of the material combination on the fitted mean roughness with coating pressure $p=2.90 \pm 0.02$ mTorr, $24 \%$ of $\mathrm{N}_{2}$, separator plates, $\Gamma=0.43 \pm 0.03$ based on 3 sets of data

\begin{tabular}{ccccc}
\hline \hline $\begin{array}{c}\text { Material } \\
\text { combination }\end{array}$ & $\begin{array}{c}\text { Fitted } \\
\text { period }[\AA]\end{array}$ & $\begin{array}{c}\text { Fitted mean } \\
\text { roughness }[\AA]\end{array}$ & $\begin{array}{c}\text { Light material } \\
\text { coating rate }\left[\AA \cdot \mathrm{s}^{-1}\right]\end{array}$ & $\begin{array}{c}\mathrm{Ni} \\
\text { coating rate }\left[\AA \cdot \mathrm{s}^{-1}\right]\end{array}$ \\
\hline \multirow{2}{*}{$\mathrm{Ni} / \mathrm{C}$} & $27.60 \pm 0.35$ & $3.83 \pm 0.12$ & $0.46 \pm 0.05$ & \\
& $62.20 \pm 5.82$ & $5.60 \pm 0.36$ & & \multirow{2}{*}{$0.20 \pm 0.01$} \\
& & & \\
$\mathrm{Ni} / \mathrm{B}_{4} \mathrm{C}$ & $27.47 \pm 0.38$ & $6.33 \pm 0.31$ & \multirow{2}{*}{$0.41 \pm 0.05$} & \\
& $61.80 \pm 0.82$ & $7.17 \pm 0.76$ & & \\
\hline \hline
\end{tabular}

Table 1: Impact of material combination with coating pressure $p=2.90 \pm 0.02 \mathrm{mTorr}, 24 \%$ of $\mathrm{N}_{2}$, separator plates, $\Gamma=0.43 \pm 0.03$ based on 3 sets of data 


\begin{tabular}{ccccc}
\hline \hline $\begin{array}{c}\text { Coating gas } \\
\text { composition }\end{array}$ & $\begin{array}{c}\text { Fitted } \\
\text { period }[\AA]\end{array}$ & $\begin{array}{c}\text { Fitted } \\
\text { mean } \\
\text { roughness }[\AA]\end{array}$ & $\begin{array}{c}\mathrm{C} \text { coating } \\
\text { rate }\left[\AA \cdot \mathrm{s}^{-1}\right]\end{array}$ & $\begin{array}{c}\text { Ni coating } \\
\text { rate }\left[\AA \cdot \mathrm{s}^{-1}\right]\end{array}$ \\
\hline & $25.00 \pm 1.00$ & $8.30 \pm 0.20$ & & \\
$\mathrm{Ar}(100 \%)$ & $49.50 \pm 1.00$ & $9.10 \pm 0.20$ & $0.14 \pm 0.01$ & $0.30 \pm 0.02$ \\
& $81.50 \pm 1.00$ & $9.90 \pm 0.20$ & & \\
& $122.00 \pm 1.00$ & $11.30 \pm 0.20$ & & \\
\hline & & & & \\
$\mathrm{Ar}(76 \%)$ & $55.50 \pm 1.00$ & $5.50 \pm 0.20$ & $0.43 \pm 0.08$ & $0.20 \pm 0.02$ \\
$+\mathrm{N}_{2}(24 \%)$ & $89.50 \pm 1.00$ & $7.00 \pm 0.20$ & & \\
& $135.00 \pm 1.00$ & $7.60 \pm 0.20$ & & \\
\hline \hline
\end{tabular}

Table 2: Impact of $\mathrm{N}_{2}$ with coating pressure $p=2.90 \pm 0.03$ mTorr, separator plates, $\Gamma=0.41 \pm 0.05, \mathrm{Ni} / \mathrm{C}$ based on 1 set of data

\subsection{Gas composition (reactive sputtering)}

The inert gas used here was Ar and the reactive gas $\mathrm{N}_{2}$. The presence of $\mathrm{N}_{2}$ is known to lower the roughness. ${ }^{7}$ The process that lowers the roughness is not well understood but the reactivity of $\mathrm{N}_{2}$ interacting on the surface at an atomic level is assumed to play a role. Moreover $\mathrm{N}_{2}$ will be included in $\mathrm{Ni}$ and $\mathrm{C}$ deposited but in which concentration is not investigated and not taken into account in the IMD fit.

First a comparison was made between coatings performed with pure Ar and coatings performed with a mixture of $\mathrm{Ar}$ and $\mathrm{N}_{2}$. Figure 4 displays the fitted mean roughnesses of four coatings as a function of their fitted bilayer periods $(\approx 25 \AA, \approx 50 \AA, \approx 80 \AA$ and $\approx 120 \AA)$ both for a coating performed with pure Ar and with a composition of $76 \%$ Ar and $24 \% \mathrm{~N}_{2}$. Moreover the material combination used was $\mathrm{Ni} / \mathrm{C}$, the coating pressure was $\approx 2.90 \pm 0.03$ mTorr, separator plates were used as collimation and the fitted $\Gamma$ value is $0.41 \pm 0.05$. The presence of $\mathrm{N}_{2}$ reduced the fitted mean roughness by a factor of $\approx 1.70$. Similarly to the material combination investigation, note that the mean roughness increase with the increase of bilayer period.

Figure 5 shows $\mathrm{XRR}$ data at $\approx 8 \mathrm{keV}$ at grazing angles from 0 degree to 3 degrees. The grazing angle is the angle between the X-ray beam and the surface of the coated substrate. Also plotted is the best IMD fit obtained manually with a bilayer period of $27.90 \AA$, a mean interface roughness of $3.8 \AA$, and a $\Gamma$ of 0.45 corresponding to the first point of Figure 4 with a mixture of $\operatorname{Ar}(76 \%)$ and $\mathrm{N}_{2}(24 \%)$ and separator plates. The critical angle (drop at $\approx 0.30-0.35$ degree) is well fitted as well as the Bragg peak (large lobe at $\approx 1.45-1.75$ degree) but the height of the Kiessig fringes (smaller lobes from $\approx 0.35$ degree to $\approx 1.45$ degree and from $\approx 1.75$ degree) is off.

Table 2 displays the fitted bilayer periods and fitted mean roughnesses along with the coating rates for $\mathrm{C}$ and Ni. The presence of $\mathrm{N}_{2}$ boosted the coating rate of $\mathrm{C}$ from $\approx 0.14 \AA \cdot \mathrm{s}^{-1}$ to $\approx 0.43 \AA \cdot \mathrm{s}^{-1}$ (factor of $\approx 3.07$ ) while the coating rate of $\mathrm{Ni}$ is reduced from $\approx 0.30 \AA \cdot \mathrm{s}^{-1}$ to $\approx 0.20 \AA \cdot \mathrm{s}^{-1}$ (factor of $\approx 1.5$ ). With $\Gamma \approx 0.41$ this corresponds to a coating process going $\approx 1.63$ times faster.

\subsection{Collimation}

Collimation techniques impact the roughnesses and coating rates. ${ }^{5}$ Set ups with separator plates and honeycomb are compared here.

Figure 6 displays the fitted mean roughness as a function of the fitted bilayer period for both separator plates and honeycomb for a coating pressure of $\approx 2.92$ mTorr, a material combination of $\mathrm{Ni} / \mathrm{C}$ and the fitted $\Gamma$ is $\approx 0.42$. 


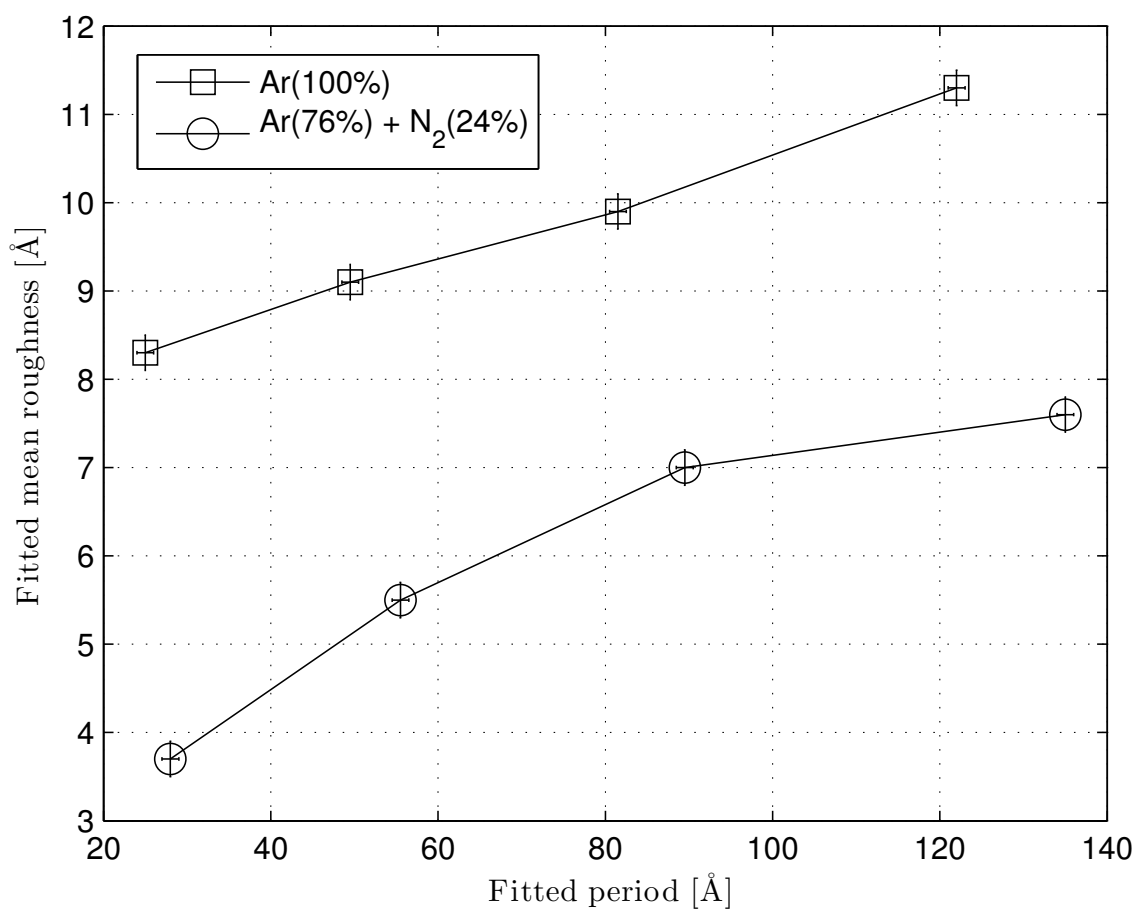

Figure 4: Impact of $\mathrm{N}_{2}$ on the fitted mean roughness with coating pressure $p=2.90 \pm 0.03$ mTorr, separator plates, $\Gamma=0.41 \pm 0.05, \mathrm{Ni} / \mathrm{C}$ based on 1 set of data

The roughness seems lower with separator plates for bilayer periods $\approx 25 \AA$. The higher roughnesses when bilayer periods increase appear less dramatic with honeycomb and from $\approx 40 \AA$ the honeycomb technique resulted in lower roughnesses. Moreover note once again the increase of mean roughness with the increase of bilayer period.

Table 3 also shows that the coating rate for $\mathrm{C}$ drops to $\approx 0.23 \AA \cdot \mathrm{s}^{-1}$ from $\approx 0.43 \AA \cdot \mathrm{s}^{-1}$ (factor of $\approx 1.89$ ) with honeycomb. The coating rate for $\mathrm{Ni}$ also dropped, from $\approx 0.20 \AA \cdot \mathrm{s}^{-1}$ to $\approx 0.11 \AA \cdot \mathrm{s}^{-1}$ (factor of $\approx 1.82$ ). To compare, the coating rate for $\mathrm{C}$ with separator plates and only $\mathrm{Ar}$ as coating gas was $\approx 0.14 \AA \cdot \mathrm{s}^{-1}(\approx 1.64$ times slower) while for $\mathrm{Ni}$ it was $\approx 0.30 \AA \cdot \mathrm{s}^{-1}(\approx 2.73$ times faster). Finally for $\Gamma \approx 0.41$ the coating with honeycomb and $\mathrm{N}_{2}$ took $\approx 1.14$ times longer than a coating with separator plates and Ar only and $\approx 1.86$ longer than a coating with separator plates and a mixture of $\mathrm{Ar}$ and $\mathrm{N}_{2}$.

\section{DEPTH-GRADED COATING}

In the light of the results obtained from the investigation of coating methods the optimized values for the parameters were selected. The material combination chosen was $\mathrm{Ni} / \mathrm{C}$, the gas composition was $\mathrm{Ar}$ and $\mathrm{N}_{2}$ and honeycomb as collimation technique was chosen over separator plates despite the slower coating rate it implied. The mean roughness was considered as the primary characterization parameter and the duration estimated for this depth-graded multilayer coating was about 6 hours which is manageable.

\subsection{Power-law}

The depth-graded multilayer coating deposited is composed of $n=150$ bilayers of Ni/C composition. The bilayer thicknesses follow a power-law such as for the layer $i \in \llbracket 1, n \rrbracket$ and with $a, b$ and $c \in \mathbf{R}$

$$
d(i)=\frac{a}{(b+i)^{c}} .
$$




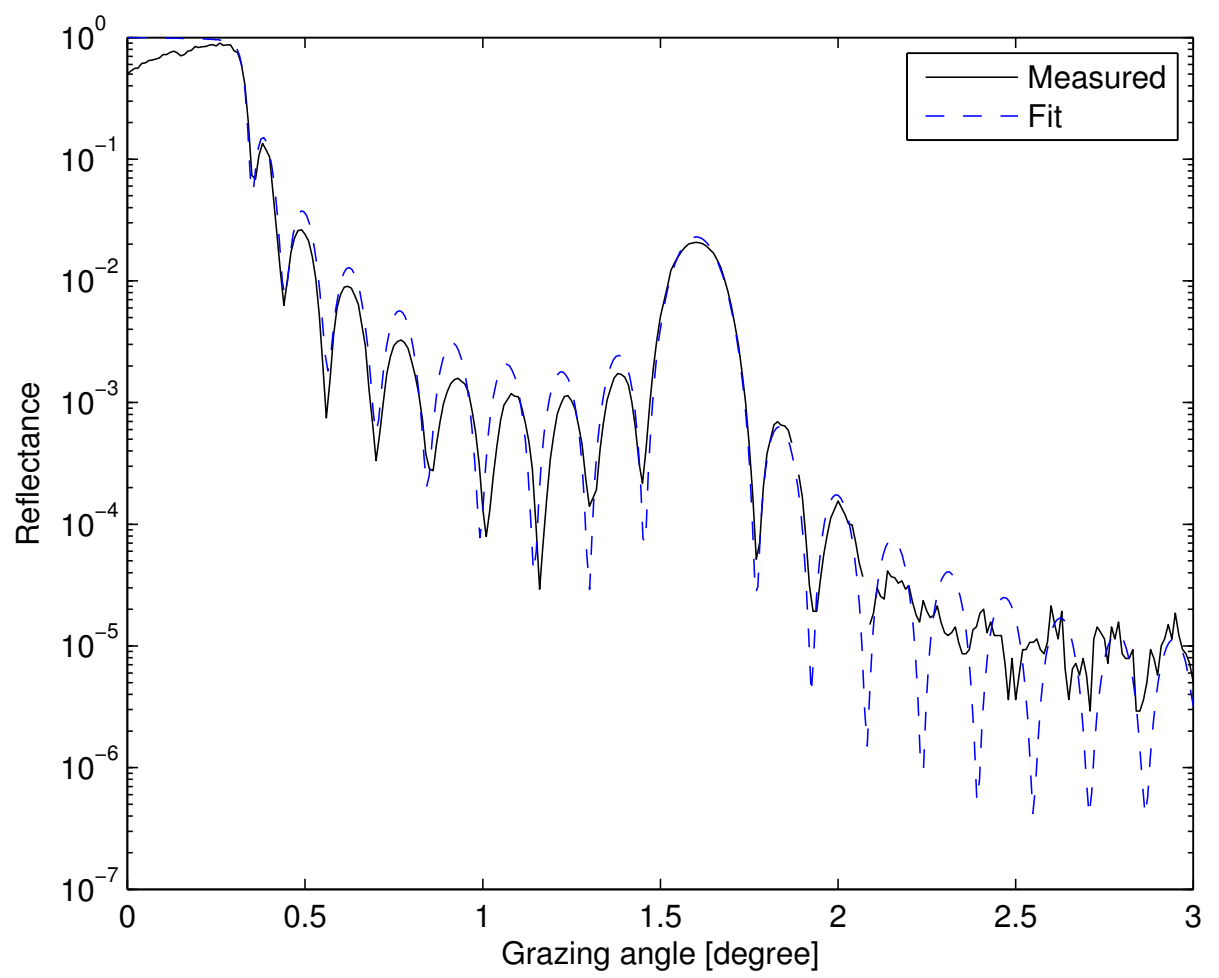

Figure 5: $\approx 8 \mathrm{keV}$ measured reflectance and IMD manual fit with a bilayer period of $27.90 \AA$, a mean interface roughness of $3.8 \AA$, and a $\Gamma$ of 0.45 corresponding to the first point of Figure 4 with a mixture of $\operatorname{Ar}(76 \%)$ and $\mathrm{N}_{2}(24 \%)$ and separator plates (a color version of this figure is available in the online proceeding)

\begin{tabular}{ccccc}
\hline \hline $\begin{array}{c}\text { Collimation } \\
\text { technique }\end{array}$ & $\begin{array}{c}\text { Fitted } \\
\text { period }[\AA]\end{array}$ & $\begin{array}{c}\text { Fitted } \\
\text { mean } \\
\text { roughness }[\AA]\end{array}$ & $\begin{array}{c}\mathrm{C} \text { coating } \\
\text { rate }\left[\AA \cdot \mathrm{s}^{-1}\right]\end{array}$ & $\begin{array}{c}\text { Ni coating } \\
\text { rate }\left[\AA \cdot \mathrm{s}^{-1}\right]\end{array}$ \\
\hline Separator \\
plates & $\begin{array}{c}28.00 \pm 1.00 \\
55.50 \pm 1.00\end{array}$ & $\begin{array}{l}3.70 \pm 0.20 \\
5.50 \pm 0.20\end{array}$ & & \\
& $89.50 \pm 1.00$ & $7.00 \pm 0.20$ & $0.43 \pm 0.08$ & $0.20 \pm 0.02$ \\
& $135.00 \pm 1.00$ & $7.60 \pm 0.20$ & & \\
\hline \multirow{4}{*}{ Honeycomb } & $24.10 \pm 1.00$ & $4.50 \pm 0.20$ & & \\
& $72.50 \pm 1.00$ & $4.30 \pm 0.20$ & $0.23 \pm 0.04$ & $0.11 \pm 0.01$ \\
& $102.50 \pm 1.00$ & $5.50 \pm 0.20$ & & \\
\hline \hline
\end{tabular}

Table 3: Impact of collimation technique with coating pressure $2.93 \pm 0.03$ mTorr , $24 \%$ of $\mathrm{N}_{2}, \mathrm{Ni} / \mathrm{C}, \Gamma=$ $0.42 \pm 0.03$ based on 1 set of data 


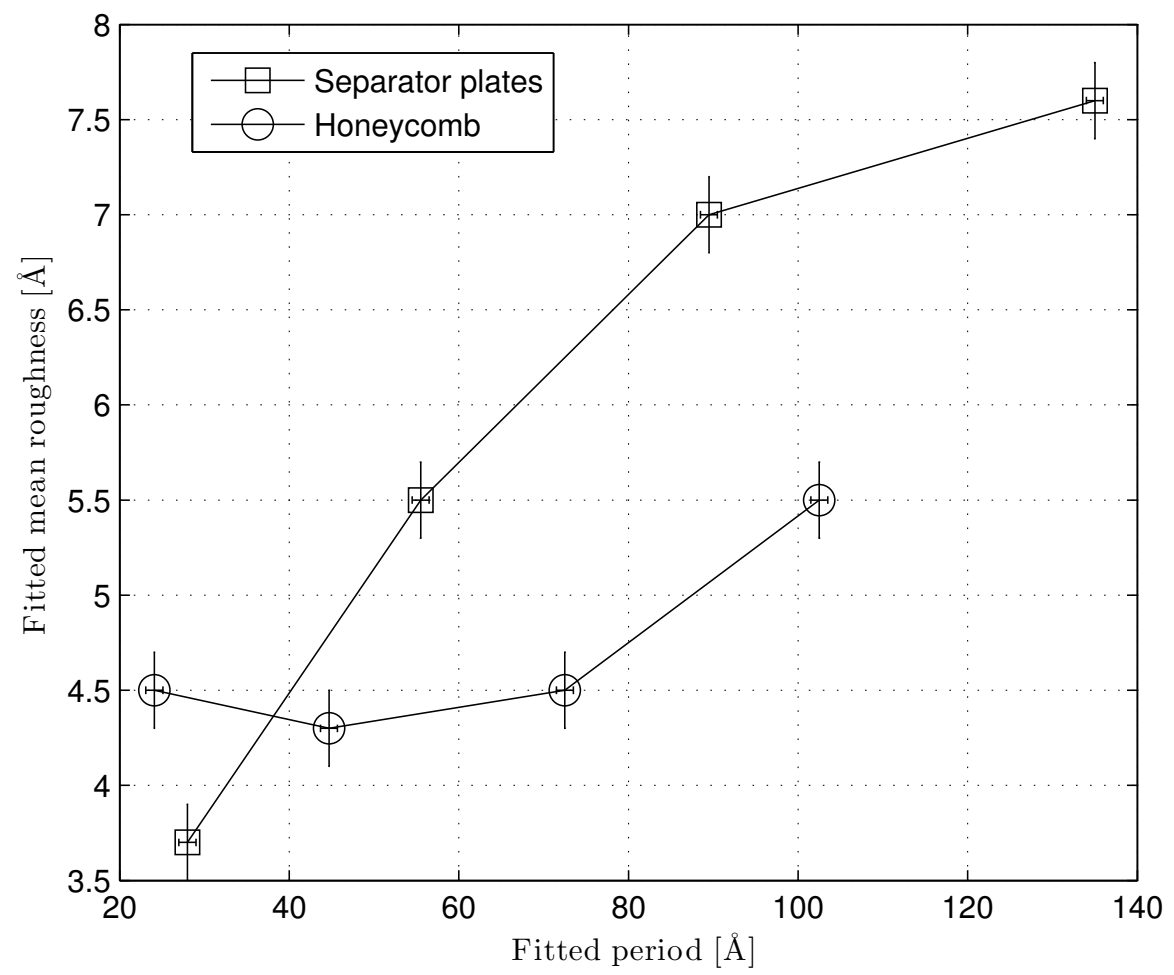

Figure 6: Impact of collimation technique with coating pressure $2.93 \pm 0.03 \mathrm{mTorr}, 24 \% \mathrm{~N}_{2}, \mathrm{Ni} / \mathrm{C}, \Gamma=0.42 \pm 0.03$ based on 1 set of data

The bilayer $i=n=150$ corresponds to the bottom layer (the one in contact with the silicon substrate) and is the thinnest bilayer of thickness

$$
d(i=150)=d_{\text {min }}=25 \AA
$$

that reflects the more energetic photons (smaller wavelength) that make their way through all the layers without being reflected. This value corresponds to the lowest bilayer thickness achievable with the coating facility at DTU Space. The bilayer $i=1$ corresponds to the top layer and is the thickest bilayer with a thickness

$$
d(i=1)=d_{\max }=120 \AA .
$$

Moreover the value of $c$ is set to

$$
c=0.25 .
$$

$d_{\text {max }}$ and $c$ are chosen to mimic the optimized NuSTAR multilayer design. ${ }^{6}$ From this $a$ and $b$ are derived and

$$
\begin{aligned}
& a \approx 87.39, \\
& b \approx-0.72 .
\end{aligned}
$$

\subsection{Calibration}

$90 \%$ of the bilayer thickness values are comprised between $25 \AA$ and $45 \AA$. Therefore a first coating called calibration run was performed with two silicon substrates to aim for depositing ten bilayers with these two bilayer thicknesses. Moreover the mean bilayer thickness value within the $90 \%$ is $d \approx 30 \AA$.

The DC magnetron sputtering chamber has an outer ring on which the Si substrates are fixed. This ring rotates inside the chamber and passes by the targets (up to four) fixed on an inner static ring. The outer ring 
velocity (in steps per second, one full rotation corresponds to 668,000 steps) is directly linked to the thickness of the layer deposited on the substrate. For this depth-graded multilayer coating it was chosen to use a constant ring velocity per bilayer (which means the ring velocity is the same for $\mathrm{Ni}$ and for $\mathrm{C}$ in a bilayer). In this configuration the ring is rotating in the same direction and one bilayer is deposited for every full rotation. This constant ring velocity is derived from a reference ring velocity $v_{r e f}$ obtained through a linear fit (ring velocity as function of bilayer thickness) of the calibration run results. Here two targets of $\mathrm{C}$ and one target of Ni were used which leads to $v_{r e f}=5515 \mathrm{step} \cdot \mathrm{s}^{-1}$ for a reference bilayer thickness of $d_{r e f}=30 \AA$. Then for each bilayer thickness, the ring velocity was computed by scaling the reference velocity such as

$$
v(d)=\frac{d_{r e f}}{d} v_{r e f}
$$

Note that the power provided to the cathodes in which the targets sits also impacts the coating rates. Here it was set to $1000 \mathrm{~W}$ for each $\mathrm{C}$ target and $606 \mathrm{~W}$ for the Ni target.

\subsection{Hard X-ray reflectometry}

After the coating process, hard X-ray reflectometry (HXRR) was performed at RXO at fixed grazing angles for energies ranging from $10 \mathrm{keV}$ to $150 \mathrm{keV}$. Figure 7 displays the measured reflectance from $10 \mathrm{keV}$ to $150 \mathrm{keV}$ for the grazing angles 0.10 degree, 0.15 degree and 0.20 degree. As expected the reflectance decreases when the grazing angle increases. An important drop in reflectance from $\approx 0.95$ to $\approx 0.20$ is seen at $\approx 25 \mathrm{keV}, \approx 17 \mathrm{keV}$ and $\approx 12 \mathrm{keV}$ for a grazing angle of respectively 0.10 degree, 0.15 degree and 0.20 degree. For each grazing angle the other features are believed to be the consequence of several issues. The coating process experienced several dropouts for unknown reasons leading to errors in the layer thicknesses and possibly the number of layers. Moreover the computation of the aimed bilayer thickness values from a reference of $30 \AA$ might have lead to errors for the larger bilayers. Finally the interface roughnesses are expected to be high due to the high number of layers, especially the ones corresponding to the top layers as the investigation of coating method revealed an increase in mean roughness with a larger bilayer thickness. Nevertheless for a grazing angle of 0.10 degree the reflectance is at least $10 \%$ up to $85 \mathrm{kev}$.

\section{SUMMARY}

Investigating the coating methods lead to several results. The material combination Ni/C coatings showed a fitted mean roughness $\approx 1.5$ times lower than the material combination $\mathrm{Ni} / \mathrm{B}_{4} \mathrm{C}$. Reactive sputtering with a mixture of $\approx 76 \%$ Ar and $\approx 24 \% \mathrm{~N}_{2}$ reduced the mean interface roughness by a factor of $\approx 1.7$, increased the coating rate of $\mathrm{C}$ by a factor of $\approx 3.1$ and shortened the coating process by a factor of $\approx 1.6$. Honeycomb collimation showed to limit the increase of mean roughness with the increase of bilayer thickness while slowing down the coating process by a factor of $\approx 1.9$.

A Ni/C 150 bilayers depth-graded multilayer coating was deposited using reactive sputtering with a mixture of $\approx 76 \%$ Ar and $\approx 24 \% \mathrm{~N}_{2}$ and honeycomb collimation. The process lasted 6 hours and the coatings was characterized at RXO from $10 \mathrm{keV}$ to $150 \mathrm{keV}$. $10 \%$ reflectance up to $85 \mathrm{keV}$ was measured. Errors in layer thicknesses due to power dropouts and calibration method and high interface roughnesses limit the measured reflectance. A better process control and calibration for high bilayer thicknesses should lead to coatings closer to the theory. These results are promising and show that Ni/C depth-graded multilayer coatings for hard $\mathrm{X}$ ray telescopes (energies greater than $80 \mathrm{keV}$ ) are possible by combining honeycomb collimation and reactive sputtering.

\section{ACKNOWLEDGMENTS}

Thanks to David L. Windt from RXO for welcoming us into his facility in New York City, for performing HXRR on the depth-graded coating and for his useful advices and feedbacks about our work. 


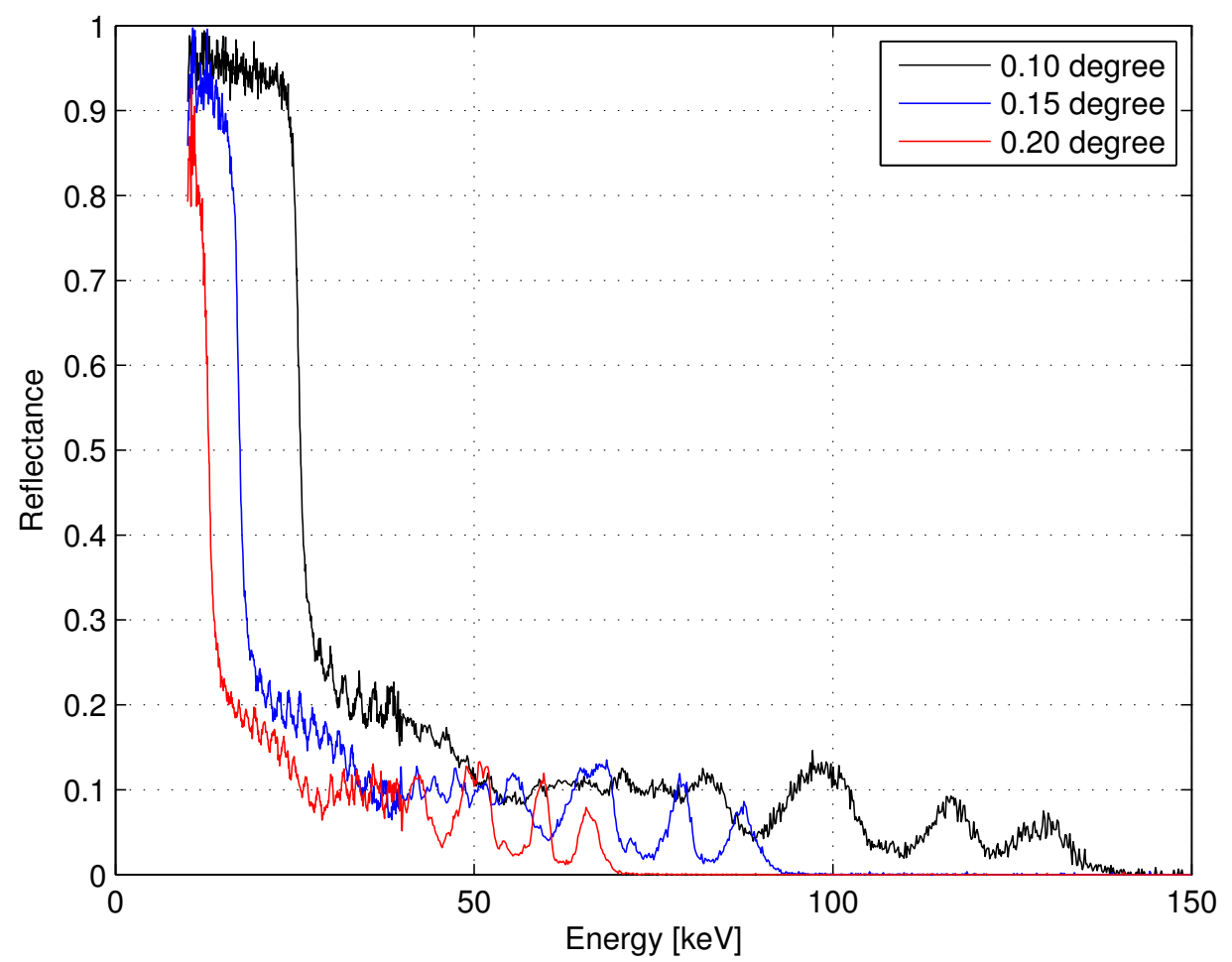

Figure 7: Measured reflectance from $10 \mathrm{keV}$ to $150 \mathrm{keV}$ at three grazing angles, 0.10 degree, 0.15 degree and 0.20 degree (a color version of this figure is available in the online proceeding) 


\section{REFERENCES}

[1] Harrison, F. A. et al., "The Nuclear Spectroscopic Telescope Array (NuSTAR) High-energy X-Ray Mission," The Astrophysical Journal 770(2), 103 (2013).

[2] Takahashi, T. et al., "The ASTRO-H Mission," in [Society of Photo-Optical Instrumentation Engineers (SPIE) Conference Series], Society of Photo-Optical Instrumentation Engineers (SPIE) Conference Series 7732, 0 (July 2010).

[3] Windt, D. L., "IMD-Software for modeling the optical properties of multilayer films," Computers in Physics 12(4), 360-370 (1998).

[4] Windt, D. L., "Laboratory-based x-ray reflectometer for multilayer characterization in the 15-150 kev energy band," Review of Scientific Instruments 86(4), - (2015).

[5] Vickery, A., Cooper-Jensen, C., Christensen, F., Steenstrup, M., and Schnfeldt, T., "Collimated magnetron sputter deposition for mirror coatings," X-Ray Optics and Instrumentation, 9 (2008).

[6] Christensen, F., Jakobsen, A., Brejnholt, N., Madsen, K., Hornstrup, A., Westergaard, N., Momberg, J., Koglin, J., Fabricant, A., Stern, M., Craig, W., Pivovaroff, M., and Windt, D., "Coatings for the NuSTAR mission," Proceedings of SPIE-the international society for optical engineering 8147(1), 81470U-19 (2011).

[7] Jakobsen, A. C., [Developing Supermirror Optics for Hard X-rays - Characterization and Optimization of Thin Film Sputter Deposition], Master thesis (2010). 